\title{
Diş Hekimliğinde Akılcı Farmakoterapi Düzenleme Süreci
}

\author{
Ahmet Akıcı, Gökhan Göçmen
}

ÖZ

İlaçların gereksiz veya yanlış kullanımı, dünya genelinde yaygın bir sorundur. Hekimlerin akılcı ilaç kullanımı (AİK) ilkelerine uygun yaklaşım sergilememesi ve buna ilişkin eğitim eksiklikleri, sorunun önde gelen nedenleri arasındadır. AİK, "ilaçların hastaların klinik ihtiyaçlarına uygun şekilde, uygun dozlarda, yeterli sürede, kendilerine ve topluma en düşük maliyette almaları” olarak tanımlanmaktadır. Diş hekimleri (DH) analjezikler ve antibiyotikler başta olmak üzere, alanlarına özgü hatırı sayılır miktarda ilacı reçete etmektedir. Diş hekimliğinde AİK’i yaygınlaştırma faaliyetlerine acil ihtiyaç duyulmaktadır. $\mathrm{Bu}$ yazıda, "hasta başında tedavi düzenleme işlemi'nin AİK ilkelerine uygun nasıl yapılması gerektiği’ üzerinde durulmaktadır. Bu süreç yazıda, aynı zamanda "analjezik tedavisi" örneği üzerinden simüle edilerek de paylaşılmıştır. Buna göre DH, doğru tanıyı takiben uyguladığ diğer dental işlemlerin yanı sıra, farmakoterapi düzenlemeyi düşündügü hastada, reçetelemeyi planladığı ilacın hastaya uygunluğunu değerlendirir. Hastaya hastalığı, tedavi gerekçesi, tedavinin bileşenleri, yaşam biçimine uyarlaması gerektirenler de dahil yapması gerekenleri anlatır. Farmakoterapiye ilişkin talimat ve uyarılarda bulunup takip işlemi vb. konularda açıkça bilgilendirir. $\mathrm{DH}$, bu süreçte hastayı olabildiğince tedavinin ortak katılımcısı yapar ve tedaviyi başarıyla yönetir.

Anahtar kelimeler: Akılcı ilaç kullanımı; Diş hekimi; Mezuniyet, Rasyonel farmakoterapi; Eğitim.
Ahmet Akıcı

Marmara Üniversitesi, Tip Fakültesi Tibbi Farmakoloji Anabilim Dal, İstanbul

Gökhan Göçmen

Marmara Üniversitesi, Diş Hekimliği Fakültesi Ağız, Diş ve Çene Cerrahisi Anabilim Dal, İstanbul

Sorumlu Yazar:

Ahmet Akıc1

e-posta:aakici@marmara.edu.tr
Submitted / Gönderilme: 25.10.2016

Accepted / Kabul: 23.12.2016

Revised / Düzeltme: 23.12.2016

\section{Giriş}

İlaç, sağlığı koruma, bozulduğunda onu yeniden kazanma ve sağlıklı olma halini sürdürme gibi amaçlarla sıkça kullanılan vazgeçilmez bir üründür. İlaç kullanımının akılcı olması esastır. İlaç, tüketicisinin hakkında en sınırlı bilgiye sahibi olduğu ürünlerden biridir. Bu nedenle kullanımıyla ilgili süreç bilirkişilere ihtiyaç duyar. Bu özel ürün, akılcı ilkelere uyulmadan kullanıldığında kendinden beklentileri karşılayamadığı gibi kendisi başlı başına önemli sağlık sorunlarına yol açabilir (1-3). Dünya Sağlık Örgütü (DSÖ), akılcı ilaç kullanımını (AİK); "ilaçların hastaların klinik ihtiyaçlarına uygun şekilde, uygun dozlarda, yeterli sürede, kendilerine ve topluma en düşük maliyette almaları olarak tanımlamıştır (2).

Akılcı olmayan ilaç kullanımı (AOİK) sorunu ile son yıllarda giderek daha sık karşılaşılmaktadır. AOİK, altta yatan pek çok nedenle ilişkili, halk sağlığını yakından ilgilendiren evrensel bir sorundur. Türkiyéde ve dünyada kullanılmakta olan ilaçların yarıya yakının AOİK sorunu ile karşılaştığı bildirilmektedir. Oysa hastaların konuya 
ilişkin bilgi düzeyinin artırılması başta olmak üzere, çeşitli yollarla bu sorunun en aza indirilmesi mümkündür (25). Hekimlerin hastalarını bilgilendirmemesi de dahil terapötik yetkinliklerinin yetersizlikleri, AOİK sorunun önde gelen nedenleri arasında yer almaktadır (6-7). AOİK, başta hekimler olmak üzere sağlık çalışanlarını yakından ilgilendiren pek çok olumsuzluğa yol açmaktadır (1-3). Örneğin tedavide başarısızlıklar yaşanması, bazı ilaçlara karşı direnç gelişmesi, mevcut hastalığın şiddetlenmesi veya yayılması, hasta güvenliğinin sıkıntıya sokulması, malpraktise ve sınırlı kaynakların israfına yol açılması, mesleki tatminsizlik oluşturması, iletişim ve güven kaybı yaşanması DH' leri de yakından ilgilendiren olumsuzluklar arasında sayılabilir (1-3, 8-10).

AOİK sorunlarının temelinde, sağlık çalışanlarının mezuniyet öncesi dönemde ve mezuniyet sonrası sürekli eğitimleri kapsamında AİK ile ilgili yeterli eğitimi alamamalarının önemli ölçüde rolü bulunmaktadır $(3,11)$. Sorunun çözümünde pek çok muhataba önemli işlevler düşmekle birlikte öncelik sağlık çalışanlarındadır. $\mathrm{Bu}$ çerçevede hekimin hem diğer sağlık çalışanlarını hem de hastalarını düzenlediği tedavi başta olmak üzere AİK ile ilgili konularda bilgilendirme yükümlülüğü bulunmaktadır. Hekim, farmakoterapi sürecini yönetirken önceden titiz uğraşla belirlediği, etkinliği kanıtlanmış tedaviyi hastasına uygular. Bu yazıda ayrıntısı sunulan şekilde hasta başında izleyeceği sistematik bir yaklaşımla, farmakoterapi düzenleme işlemini başarıyla yönetir ve böylece olası AOİK sorunlarının üstesinden gelmesi kolaylaşır $(1,11)$.

Literatüre yansıyan sonuçlar, AİK ile ilgili eğitim faaliyetlerinin, ilaç seçme, reçete yazma, tedavisi ile ilgili hastasını bilgilendirme, iyi iletişim kurma vb. konularda hekimlerin terapötik yetkinliklerini artırdığına işaret etmektedir (1-3, 6, 12-16). Sorunun çözüm önerileri arasında probleme dayalı akılcı farmakoterapi (PDAF) eğitimleri önemli yer tutmaktadır. Tip ve eczacilıkta bu yönde AİK eğitimleri mezuniyet öncesi ve sonrası için uzun yıllardan beri başarıyla uygulanmaktadır $(1,6,11-18)$. Benzeri eğitimlerin diş hekimliğinde farmakoterapi düzenleme sürecine de başarıyla uyarlanabileceği savunulmaktadır.

\section{Diş Hekimliğinde İlaç Kullanımının Boyutları}

Diş hekimleri (DH), analjezikler ve antibiyotikler başta olmak üzere, alanlarına özgü hatırı sayılır miktarda ilacı reçete etmektedir. Örneğin, Örneğin, Birleşik Krallık’ta yapılan çalışmalarda yazılan her 10 antimikrobiyal ilaçtan 1 tanesinin diş hekimlerince yazdığı rapor edilmiştir (19-20). Diş hekimlerinin antibiyotik yazdıkları reçetelere çoğunlukla analjezik de yazma eğilimi sergiledikleri bildirilmiştir (21). $\mathrm{Bu}$ ilaçların istenen ölçüde akılcı kullanıldığını söylemek güçtür $(22,23)$. Yapılan araştırmalar diş hekimlerinin ilaç yazma kararı aldıkları endikasyonların sorgulanması gerektiğini, bununla ilgili belirli düzenlemelerin yapılması ihtiyacının bulunduğu gerçeğini açığa çıkarmıştır $(24,25)$. Diş hekimleri arasında antibiyotik ve analjezikler başta olmak üzere ilaçların gereksiz/aşırı reçete edildiğine yönelik tartışmalar bulunmaktadır (26). Bu sorun, reçeteleme ile ilgili eksikliklerin yanı sıra ilacın uygulanmasını, yanlış kullanılmasını ilgilendiren pek çok problemi de içermektedir (26-29). Tüm bu olumsuzluklar birlikte değerlendirildiğinde mevcut durum, diş hekimliğinde AİK ilkelerine uygun hareket edilmesinin gereğini yansıtmaktadır. Sorunun çözümünde tıpta olduğu gibi diş hekimliğinde de PDAF eğitimlerinin etkin şekilde verilmesi gerekir. Belirli bir planlama çerçevesinde hayata geçirilecek bu gibi eğitimlerin diş hekimliği fakülteleri öğrencilerinin yanı sıra mezun olan DH'ler için de uygulanması, AİK’in yaygınlaştırılmasına önemli katkılar sunabilir. Bunun için çeşitli girişimler son zamanlarda hız kazanmıştır. Nitekim, Türkiyede sağlık otoritesinin başlattığı AİK’i yaygınlaştırmaya yönelik "Akılcı İlaç Kullanımı Ulusal Eylem Planı" kapsamında "diş hekimliği fakültelerinin eğitim müfredatlarına AİK ile ilgili ders ve staj programlarının eklenmesi” istenmiştir (31). Bu olumlu gelişmelerin amacına hızla ulaşabilmesi için, özellikle eğitim alanında hazırlıklı olmaya gereksinim duyulmaktadır $(2,3)$. Bu yazıda, mezuniyet öncesi ve sonrası diş hekimliği eğitimlerinde kullanılabilecek, PDAF eğitimi çerçevesinde hastaların ilaç tedavisi düzenleme sürecinin ayrıntıları üzerinde durulmaktadır.

\section{Diş Hekimlerine Yönelik PDAF Eğitimi}

AİK’e uygun davranan bir diş hekiminin, öncelikle reçeteleyebileceği ilaçlar konusunda yeterli farmakoloji bilgisine sahip olması gerekir. Bu önkoşulu sağlayan hekimin hastalıkların tedavisinde alternatifleri arasında en iyisini belirleme becerisini kazanmış olması beklenir (3, 3234). Hekimin tedavi ve ilaç seçimini kanıta dayalı güncel bilgiler doğrultusunda kendi kişisel yaklaşımıyla belirlemesi beklenir. Hekim, ilgili endikasyonda alternatifleri arasında en iyi tedaviyi ve bunların ilaç içerenleri için ilacı, "etkililik, güvenlilik, uygunluk ve maliyet" seçim ölçütlerine göre önceden belirler. Bu hazırlık sonrası hastasının farmakoterapi düzenleme işlemine girişen bir hekim, reçetelemeyi 
planladığı ilacın o sırada karşısındaki hastaya uygunluğunu değerlendirir ve süreci açık, anlaşılır bir dille, hastayı da tedavinin ortak katılımcısı kılarak başarıyla yönetir $(1,11$, 33). DSÖ tarafından ortaya çıkartılmasına katkı sunulan ve başarılı pek çok uygulaması nedeniyle tüm dünyada hayata geçirilmesi desteklenen PDAF eğitimi modeli, günlük hayatta bazı rutin ihtiyaçların karşılanmasında yaşanan akılcı yolu taklit eder. Bu uyumu nedeniyle, hekimlerce benimsenmesi ve uygulanması oldukça kolaydır (3, 11, 32-34). Tipta mezuniyet öncesi ve sonrası yaygın olarak kullanılan bu model, diş hekimliğine de rahatlıkla uyarlanabilir $(30,32)$. Sistematik bir yaklaşımla, hastanın kolay kavrayabileceği bir sıralamayı izleyerek yürütülen bu modelin aşağıda basamakları tek tek sıralanmış ve içeriği ayrıntılı olarak paylaşılmıştır. $\mathrm{Bu}$ modelin diş hekimliğinde uygulanabilmesini kolaylaştırmak için yazıda "pulpitis" tanılı bir simüle hastada diş ağrısının giderilmesine yönelik tedavi düzenleme süreci, bir örnekle anlatılmıştır.

\section{AİK’e Uygun Farmakoterapi Düzenleme Süreci}

Hastaya anlatmak istediklerini daha başarılı aktarma imkanı sunduğu için hekim, hasta başı tedavi düzenleme ve reçete yazma işlemleri sırasında Tablo l'de sunulana yakın olabildiğince sistematik bir yol izlemelidir (1, 3, 11, 32-34).

Tablo 1: Hasta başında akılcı farmakoterapi düzenleme süreci

\begin{tabular}{|c|l|}
\hline $\begin{array}{c}\text { Uygulama } \\
\text { Basamakları }\end{array}$ & Hekimin hasta başında tedavi düzenleme işlemleri \\
\hline $\mathbf{1 .}$ & $\begin{array}{l}\text { Hastaya "doğru tanı" konmasının ardından, teşhis } \\
\text { hastaya anlatılır }\end{array}$ \\
\hline $\mathbf{2 .}$ & Tedavinin amaçları belirlenir ve hastayla paylaşılır \\
\hline $\mathbf{3 .}$ & Tedavinin uygunluğu belirlenir \\
\hline $\mathbf{4 .}$ & $\begin{array}{l}\text { Hasta için kararlaştırılan tedavinin ayrıntılarının } \\
\text { düzenlenmesine geçilir: } \\
\text { a- Tedavinin süresi söylenir. } \\
\text { b- Tedavinin ilaç-dışı kısmı hastaya anlatılır. } \\
\text { c- Tedavinin içerdiği ilaç(lar) reçete edilir }\end{array}$ \\
\hline $\mathbf{5 .}$ & $\begin{array}{l}\text { Tedavi ile ilgili bilgiler ve talimatlar verilir. Gerekli } \\
\text { uyarılarda bulunulur. }\end{array}$ \\
\hline $\mathbf{6 .}$ & $\begin{array}{l}\text { Tedavinin izleminin nasıl yapılacağı ve nasıl } \\
\text { sonlandırılacağı kararlaştırılır. }\end{array}$ \\
\hline $\mathbf{7 .}$ & $\begin{array}{l}\text { Gerekli bilgilerin hastayla paylaşıldığından ve bu } \\
\text { bilgilerin doğru anlaşıldığından emin olunmaya } \\
\text { çalışılır. }\end{array}$ \\
\hline
\end{tabular}

$\mathrm{Bu}$ yaklaşım, diş hekimliğinde çok daha kritik önem arz eder. Diş hekimliğindeki pratiklerde çoğu kez farmakoterapi düzenlemenin hemen öncesinde hastaya bir takım dental işlemler yapılmış olmaktadır. Bu işlemlerin de tesiriyle hastanın anlatılacakları kavraması ile ilgili çeşitli güçlükler yaşanabilir. Söz konusu sistematik yaklaşım hastanın farmakoterapiye ilişkin anlaması ve akılda tutması gerekenlerin yükünü hafifletir. Dolayısıyla bu yaklaşımdan hem hekim anlatacaklarını atlamadan, aksatmadan anlatma imkanı bulur hem de hasta daha fazla yarar görür.

Analjezikler diş hekimliğinde yaygın kullanılan önemli bir ilaç gurubudur $(23-25,35)$. Analjeziklerin kullanımı konusunda çeşitli AOİK sorunları yaşanmaktadır ve bunların halk sağlığını tehdit etme potansiyeli bulunmaktadır (23-25, 27, 30, 36-41). DH'lere AİK ilkelerine uygun hasta başında farmakoterapi sürecini düzenleme ile ilgili bilgi verilirken "Analjezik tedavisi düzenleme" örneği ile tedavi düzenleme süreci aşağıda paylaşılmıştır. Bu örnekte güncel kanıta dayalı bilgi çerçevesinde seçilen ilacın tedavi düzenlemesine ait ayrıntı ve tedavinin bir parçasını oluşturan ilaç dışı tedavi bilgilerinde kanıta dayalı güncel bilgilerden faydalanılmıştır (32-36, 42-45). Söz konusu olgunun tedavisinde seçilen ilaç, bu simülasyonu yapan bir DH'nin "kişisel ilaç tedavisi”nde belirlediği ilaç kurgusu üzerinden ele alınmıştır. İbuprofen bu ve benzeri durumlarda sıkça kullanılabilen bir ilaç olmakla beraber alternatifleri arasında başka analjeziklerin de bulunduğu ve bunlarında ilgili endikasyonlarda tercih edilebileceği göz önünde bulundurulmalıdır $(35,36,42)$. İlaç seçimi, bu yazının doğrudan konusu olmamakla birlikte söz konusu seçimin AİK ilkelerine uygun olarak "alternatifler arasında eniyileme analizi” yapılarak belirlenmesi tavsiye edilir. Kişisel ilaç (K-ilaç), içerisinde ilacın bulunduğu tedavinin kullanılacağı bir endikasyonda hekimin henüz hasta ile karşlaşmadan önce o endikasyon için belirlediği ve öncelik sırasına göre sıraladığı ilaç listesindeki en üst sıralarda bulunan ilaçlara verilen addır $(1,11)$. Dolayısıyla bu yaklaşımın benimsenmesi halinde hekimlere herhangi bir endikasyonda somut olarak bir ilacın kullanılması yönünde tavsiyede bulunulmaz. Aksine ilaç seçimini doğru yapma yöntemi öğretilerek hekimi bulunduğu şartlara ve benzeri pek çok faktöre bağlı olarak ilgili endikasyonda kendi kişisel ilaç listesini belirleyip bu doğrultuda en uygun tedaviyi düzenlemesi beklenir $(1,3,11,33)$. Olgunun tedavisinde kullanılan ibuprofen'in ticari isminden söz edilirken, etik nedenlerle piyasada mevcut müstahzar isimlerinden biri değil, onun yerine simüle bir isim (Dişibupro) tercih edilmiştir. Olguda sözü edilen ilacın sadece ticari ismi simüle olup, içeriği "ibuprofen" ile ilgili bilgiler, bu ilacın 
farmakolojisini ve klinikte kullanımını ilgilendiren kanıta dayalı gerçek bilimsel bilgilerden oluşmaktadır $(35,36,49$, 42).

\section{“Dental Ağrı Yakınmalı” Simüle Olguya Akılcı Farmakoterapi Düzenleme Sürecine Uygun Diş Hekimi Yaklaşımı}

\begin{abstract}
Simüle Olgu:
G.K. adlı 25 yaşındaki kadın hasta, özel bir şirkette muhasebeci olarak çalışmaktadır ve sistemik herhangi bir hastalığı bulunmamaktadır. Hasta, 24 numaralı dişinde, kendiliğinden başlayan ağrışikâyetiileçalıştığınız kliniğine başvurmuştur. Yaptığınız klinik ve radyolojik muayene sonucunda ilgili dişte pulpitis tanısı koydunuz. Başlatılan kök kanal tedavisine ek olarak bu süreçte ve sonrasında uygulaması gereken yaşam biçimi değişiklileri hakkında hastaya bilgi verdiniz. Hastanın tedavisi kapsamındaki ilk dental girişimin ertesi günü sabah, hasta ağrı şikâyeti ile tekrar kliniğginize geldi. Yaptığınız ikinci muayene ve dental işlemleri takiben evine giden hasta, öğleden sonra benzer şikâyetlerinin devam etmesi üzerine size yeniden başvurdu. Bu son değerlendirmenizde hastanın ağrı ve hassasiyetinin ilaç tedavisi gerektirdiğine karar verdiniz.

Lütfen bu hastanın ilaç tedavisini düzenleyip süreci yönetiniz.
\end{abstract}

1. Hastalığınız: pulpitis diye adlandırılan ve dişin içerisinde yer alan damar-sinir dokularının iltihaplanmasıdır. Bu hastalık, sıcak-soğuk, çiğneme veya başka pek çok nedene bağlı olarak ağrıya yol açabilir. Ağrı bezen kendiliğinden de oluşabilir. Hastalığın dental tedavisinde "kök kanal tedavisi" işlemi yapılır. Bu hastalık bir veya birkaç kez uygulanan dental işlemler ile tedavi edilirken ağrı yakınması da bu sayede ortadan kalkar. Sizde olduğu gibi bazı hastalarda ağrı yakınması yapılan dental işlemlere rağmen ilaç kullanımını gerektirebilir.

2. Tedavinizi düzenlemekteki amacımız: hastalığa bağlı iltihaplanmış, hasarlı dokuların onarılmasını sağlamak ve duymakta olduğunuz ağrıyı gidermektir. Bu tedaviler ile yaşam kalitenizi arttırmayı hedefliyoruz.

3. Düşündüğüm tedavinin size uygunluğunu belirlerken, öncelikle birkaç sorumu yanıtlamanızı isteyeceğim;

- Herhangi bir sistemik hastalığınız olmadığını daha önce söylemiştiniz. Bu tür durumalar, ilaç seçimimizi etkileyebilir. Dolayısıyla, bu durumdan eminsiniz değil mi? o Bunların dıșında aşağıdakine benzer șekilde "düşünülen tedavi ilacına özgü ilave hastalık (özellikle kontrendikasyonlar) ve durum sorgulamaları" eksiksiz yapılarak "K-ilaç uygunluğu", hasta başında karara bağlanır.

o Araştırılan hastalk(lar), durum(lar) "yok" ise, hekim önceden bu endikasyon için belirlediği K-ilacı ile tedaviyi düzenler.

o Araştırılanlar "var" ise, hekim bu yeni duruma uygun ilaç seçer ya da söz konusu var olan durumun şiddetini göz önünde bulundurularak, tedavi seçeneklerini ona göre değerlendirir yada duruma uygun ilave tedbirlere başvurur.

- Karaciğer yetmezliği, böbrek yetmezliği yada kalp yetmezliği gibi bir hastalığınız var mı?

- Önceden geçirilmiş yada halen süren herhangi bir kanama sorununuz var mı?

- Astım, döküntü gibi alerji veya aşırı duyarlılık sorununuz var mı?

- Herhangi bir ilaca veya başka şeye karşı alerjiniz var mı?

- Önceden geçirilmiş yada halen süren mide-barsak ülseri, kanaması, iltihabi barsak hastalığı vb. sindirim sistemi hastalığınız var mı?

- Şu anda hamilelik ya da emzirme gibi özel bir durumunuz var mi?

- Şu anda herhangi bir ilaç/"tıbbi amaçlı ürün" kullanıyor musunuz?

o Aspirin yada başka ağrı kesici/iltihap giderici herhangi bir ilaç kullanıyor musunuz?

İbuprofen gibi nonsteroid antiinflamatuvar ilaçlar (NSAIİ),

- Trombosit agregasyonunu kısa süreli ve geri dönüşümlü olarak inhibe ederler. Bu nedenle antikoagülan alanlarda dikkatli olunmalıdır.

- Aspirin yada diğer NSAIII'ler yada steroidler ile birlikte kullanımında başta gastrointestinal sistem karşıt etkileri olmak üzere istenmeyen etkileri artabilir.

- Aspirinle birlikte kullanımında aspirinin bazı etkilerinin azaltabilir.

- Anjiotensin dönüştürücü enzim inhibitörleri gibi antihipertansif ilaçların etkilerini azaltabilirler.

-Aminoglikozid grubu antibiyotiklerin ya da lityumun atılımını azaltarak, bu ilaçların etkilerini/karşıt etkilerini artırabilirler. 
- Sosyal güvenceniz var mı? / İlacın satın almada ekonomik açıdan sorun yaşanabilir mi?

Ekonomik açıdan hastanın alım gücü uygunsa, hekim önceden bu endikasyon için belirlediği K-ilacı ile tedaviyi düzenler. Bu bakımdan sorun varsa, bu yeni duruma uygun ilaç seçer.

4. Düzenlemeyi planladığım tedavinizi (Vermiş olduğunuz bu yanıtların da katkısıyla) şu anda tam olarak belirledim. Bu tedavi ile ilgili sizi şimdi bilgilendirmeye çalışacağım ve reçetenizi yazacağım:

4a-Hastalığınız tedavi süreci: şu anda kök kanal tedavi sürecinin ortasında bulunmakta. Bu aşamada size "bazı yaşam biçimi değişikliklerini kapsayan" ilaç dışı tedaviyle birlikte, ilaç tedavisi de başlamayı planlıyorum.

- Bu tedavinin dental işlemler ile ilgili kısmı, son bir kez daha tekrarlanacaktır.

- İlaç dışı tedavi, hastalığınızın tedavisine yardımcı olacak; şikayetlerin giderilmesini kolaylaştıracak; bir sonraki randevunuza kadar sürecek uygulamalardır.

- İlaç tedaviniz, sadece bu süreçte oluşan ağrınızı gidermeye yöneliktir. Dolayısıyla ilacı diş ağrınız geçinceye kadar kullanabilirsiniz. Şayet diş ağrınız devam ederse, ilacı bir sonraki randevunuza kadar kullanabilirsiniz.

\section{4b-İlaç dışı tedavinizde}

$\mathrm{Bu}$ süreç içerisinde,

- yemek yerken ilgili dişin bulunduğu bölgeyi tedavi süresince mümkün olduğu kadar kullanmamalısınız,

- diş sorunu yaşamakta olduğunuz tarafla sert gıdaları çiğnememeye, sakız çiğnememeye ve lokum gibi geçici dolgunuzun üzerine yapışabilecek gıdalar tüketmemeye özen göstermelisiniz,

- ağız ve diş bakımını ne sıklıkta ve nasıl sağlıyorsunuz?

- (cevapyeterliise)“-rutininize devametmenizgerekmektedir.”

- (cevap yeterli değilse) "-ağız ve diş bakımınız konusunda birazdan size maket üzerinde göstereceğim doğrultuda günlük, düzenli bakımınızı aksatmadan yapmalısınız"; günde en az iki defa dişlerinizi fırçalamalı ve diş ipi kullanmalısınız (bu işlemi mevcut tedaviniz süresince hastalığınızın olduğu diş bölgesinin dışı için uygulayınız); aşırı sıcak ve soğuk, şekerli içecek ve yiyecekleri yada asiditesi fazla olan içecekleri tüketmemeye özen göstermelisiniz; ağız ve diş temizliğinizi size önerilenler dışında kürdan vb cisimler kullanarak yapmayınız.

- Sigara veya tütün ürünleri kullanıyor musunuz?

-(kullanmıyorsa) “-bu alışkanlığınız, hem genel sağlığınız hem de mevcut hastalığınız bakımından olumlu bir durumdur. Buna devam etmeniz gerekir."

- (kullanıyorsa) "-bu durum, hem genel sağlığınız açısından hem de mevcut hastalığınız açısından oldukça olumsuzdur. Tedaviniz süresince bu alışkanlığınızı kesinlikle bırakmalısınız."

4c-Tedaviniz için șu anda reçetenize bir adet ilaç yazıyorum.

\section{Yazdığım ilacınız,}

(a-Adı, içeriği, miktarı ve kullanım talimatları):

- "Dişibupro" adlı, içerisinden $200 \mathrm{mg}$ "ibuprofen" adlı ağrıkesici etken maddesi bulunan, kapsül formunda bir ilaçtır.

- İçerisinde 20 kapsül olan bu ilaçtan size kontrole gelinceye kadar yetecek olan bir kutu yazıyorum.

- Bu ilacı, ihtiyaca göre her 4 ile 6 saatte 1 veya 2 kapsül alabilirsiniz. Kapsülü, aç karnına (gerekirse yemekten sonra da olabilir) 1 bardak su ile yutarak alınız.

- Ağrınız geçerse, ilacı kullanmayı sürdürmenize gerek yoktur.

- Şayet ağrınız, ilacı almanıza rağmen geçmezse, yada mevcut halinden daha da şiddetli hale dönerse, gerektiği sürece Dişibuprơyu 4-6 saatte bir 1-2 kapsül alabilirsiniz. Ancak, 24 saat içerisinde toplam 6 kapsülden fazla almamalısınız.

\section{(b-Etkisi):}

- Dişibipro’nun ağrı kesici, iltihap giderici ve başka bazı etkileri bulunmakta.

- Size bu ilacı ağrı kesici etkisinden yararlanmak için yazıyorum.

- İlacın ağrı kesici etkisi, ağızdan alınmasını takiben 1 saat içerisinde ortaya çıkar ve 6 saat kadar sürer.

(c-Karşıt/yan etkisi): Dişibupro’yu kullanırken bir takım karşıt/yan etkiler ile karşılaşabilirsiniz

- Bu ilaç benzeri etkileri bulunan aynı gruptaki diğer ağrı kesicilere göre nispeten daha az yan etkiye yol açar ve daha iyi tolere edilir. $\mathrm{Bu}$ yan etkiler sizde kullanmay düşündügüumüz düşük doz ve kısa süreli kullanımlarda en 
az seviyeye inmektedir. Ancak yine de tedaviniz sırasında ilaca bağlı bazı sorunlarla karşılaşabilirsiniz. Bunlar arasında göreceli daha sık ve önemli olanlarına değinmek gerekirse;

- Karın ağrısı, hazımsızlık, yanma ve bulantı gibi mide/ barsak rahatsızlıkları ile karşılaşılabilir. Daha zayıf olasılık da olsa, kanama, yara oluşması, barsak delinmesi gibi hayati yan etkilerle de karşılaşılabilir.

- Seyrek olarak

- cilt döküntüsü ve kaşıntı gibi alerjik reaksiyonlar

- baş ağrısı, baş dönmesi, bulanık görme

- kanama ile ilgili kan hücrelerinin sayı ve işlevlerinde azalma

- karaciğer ve böbrek fonksiyonlarında azalma gibi sorunlar ile karşılaşılabilir.

(d-Uyarılar): Tedavinizi sürdürürken özellikle şu konularda daha dikkatli olmanız gerekir:

o İlacın bu bahsettiğim istenmeyen yan etkilerini hissederseniz, ilacı kullanmayı bırakın ve bana veya en yakın sağlık kuruluşuna başvurun.

o Size önerdiğim dozun üzerine çıkmayın. Bu miktar, günde en çok 6 kapsülü kesinlikle aşmamalıdır.

o Unutmayın, bu ilacın biraz önce saydığım yan etkileri de çoğu kez doz arttığında daha kolay oluşmaktadır.

o Şayet (kısa zaman içerisinde bile olsa), başka bir nedenle ilaç kullanmanız gerektiğinde, tedaviyi düzenleyecek hekiminize dental tedavi sürecinde olduğunuzu ve "Dişibupro" kullandığınızı mutlaka hatırlatın.

o İlaç dışı tedavi için önerdiğim bütün yaşam biçimi değişikliklerini eksiksiz uygulamalısınız. Bunlara tam uymanız, almak zorunda kalacağınız ağrı kesici miktarını ve kullanma sürenizi azaltır.

6. Kontrol için sizi üç gün sonra bekliyorum. Ancak ağrınız şu ankinden fazla olursa, yada başka bir sorunla karşılaşırsanız, daha erken de başvurabilirsiniz. Kontrole gelirken

- Tok karnına gelmeyi tercih ediniz.

- "Mevcut diş ağrınızın seyri ve tedaviye cevabı konusunda" geldiğinizde bilgi vermeniz yeterli olacaktır.

\section{7. ("İletişim-düzenlenen tedavi bilgilerinin aktarımından emin olma"):}

- Tedaviniz ile ilgili sizinle paylaşmak istediklerim, bu konuştuklarımızdan oluşuyor.
- Konuştuklarımız arasında anlamadığınız ya da sormak istediğiniz herhangi bir konu var mı?

"Var" ise, hastanın soru sormasına izin verilir ve sorusu cevaplanır. Anlaşılmayan hususlar, hastaya açık ve daha anlaşılır biçimde tekrar anlatılır.

- Tedaviniz ile ilgili sizinle paylaştığım bilgiler arasında eksik ya da yanlış anlaşılma olmaması için bu bilgileri kısaca bir de siz tekrarlar misinız?

Hastanın tedavisi ile ilgili anlatılanlar konusunda hekimle paylaştığı bilgiler arasında "eksik/hatalı bilgiler" var ise, bunlar hastaya açı ve daha anlaşılır biçimde tekrar anlatilir.

- Reçetenize yazdığım ilacınızı eczaneden alarak bugün kullanmaya başlayabilirsiniz.

- Üç gün sonraki randevunuzda görüşürüz, geçmiş olsun....

Ülkemizde en çok tüketilen ilaçlar arasında yer alan analjezikler, dental amaçlarla da oldukça geniş bir kullanım alanına sahiptir $(30,35,36)$. Hasta başında akılcı farmakoterapi düzenleme işleminin örnekle anlatımında bu nedenle analjeziğe ihtiyaç duyulan pulpitis tanılı simüle bir olgu seçilmiştir. AİK' yaygınlaştırma eğitimlerinde hekimlere hemen her konu alt başlı̆̆ında bu yola bilgi sunmak pratik değildir. Ancak seçilen isabetli konuların özelinde verilen başarılı eğitimlerin AİK açısından olumlu sonuçlar sağladığı iddia edilmektedir. $\mathrm{Bu}$ eğitimlerde konuşulmayan endikasyonlarda bile hekimlerin daha başarılı oldukları (transfer etkisi) bilinmektedir (12). Bu deneyimler doğrultusunda, yazıda çok da karmaşık olmayan ve analjezik tedavisi gerektiren bir olgu seçilmiştir. Okuyucu DH'lerin bunu farmakoterapi düzenleyecekleri diğer endikasyonlara ve ilaç gruplarıly tedavilere de akılcı şekilde transfer etmesi beklenmektedir. Öte yandan analjezik, antibiyotik ve diğer pek çok ilacın hastalar tarafından doğru kullanılmadığına dair tespitler ve bu olumsuzlukların halk sağlığını tehdit eden yönleri son yıllarda daha çok tartışılır olmuştur. AOİK sorunlarında hastaların ve onların bakımını üstlenen bireylerin de ciddi bilgi eksiklikleri bulunmaktadır (4650). Hekimin hastalarının tedavisini düzenlerken onu bu süreç hakkında yeterli düzeyde bilgilendirmesi, söz konusu bu eksiklikleri gidermenin ilk koşulunu oluşturmaktadır. Dolayısıyla, AİK'e uygun hareket edecek bir hekimin hastasının tedavisini düzenlerken onun en kolay ve kalıc1 anlayabileceği bu yöntemi benimsemesi gerekir $(1,3,11)$. Dental farmakoterapide bu güne kadar konu bu açıklıkta hiç 
gündeme getirilmemiştir. Bu bakımdan bir ilk olma niteliği taşıyan bu yazıda konunun daha iyi anlaşılması ve DH'lerce pratiğe kolayca geçirilmesi amacıyla analjezik özelinde simüle bir olguya da yer verilmiştir.

Sonuç olarak, AİK’e uygun hareket etme konusunda önemli paydaşlardan birisi olan DH'lere önemli işlevler düşmektedir. İlaçlar ile ilgili yaşanan gelişmeler göz önüne alındığında, DH'lerin eğitiminde akılcı farmakoterapinin giderek daha önemli hale gelmesi beklenmektedir. Bu bakımdan hasta başı tedavi düzenleme aşamasında DH'lerin izleyecekleri yol ile ilgili eğitimlere ağırlık verilmelidir. Bu eğitimlerin diş hekimliği öğrencilerine ve mezunlarına PDAF yoluyla verilmesinin, dental nedenlerle ilaç kullanımında daha başarılı sonuçların elde edilmesine yardımcı olması beklenmektedir. $\mathrm{Bu}$ süreci başarıyla yönetebilmesi için DH adayları fakültedeki eğitimleri sırasında, DH'ler ise mezuniyet sonrası sürekli eğitimi kapsamında iyi eğitim almalı ve imkânlar doğrultusunda bu bakımdan kendilerini sürekli geliştirmelidirler.

\section{Rational Pharmacotherapy Management Process in Dentistry}

\section{ABSTRACT}

Unnecessary or improper use of medications is a common worldwide problem. Inadequate approach of doctors to the rational use of medicine (RUM) principles and lack of its educational process are main reasons of this problem. RUM defined as "patients receive medications appropriate to their clinical needs, in doses that meet their own individual requirements, for an adequate period of time, and at the lowest cost to them and their community". Dentists prescribe serious amount of medication, which is mostly analgesics and antibiotics. Therefore, informing dentists and dissemination of RUM among them is an urgent issue. This article points out, "how to manage overall treatment process based on RUM principles next by a patient on the dental practice". In additionally, that is carried out by a simulation case requiring an analgesic drug treatment. Therefore, suitability of the drug with the patient, which is going to be prescribed after dental procedure with the correct diagnosis, will be assessed. Illness, treatment aim, participants and adaptation with the life style are explained to the patients. Dentist makes instructions and recommendations clearly about the pharmacotherapy process and informs the patient. Therefore, they integrate the patient to the overall treatment process and manage it.

Keywords: Rational use of medicine; Dentist; Graduation, Rational pharmacotherapy; Education.

\section{Kaynaklar}

1. Akıcı A, Uzuner A. Birinci Basamak Sağlık Kurumlarında Çalıșan Hekimlere Yönelik Akılcı İlaç Kullanımı, 1.Baskı [Rational Drug Use in Primary Health Care Physicians]. Editör: Akıcı A. T.C. Sosyal Güvenlik Kurumu Başkanlığı, Ankara. 2013, pp 25-93.

2. World Health Organization (WHO). Promoting rational use of medicines: core components, policy perspectives on medicines. Geneva: WH. 2002.

3. Akıcı A. Akılcı ilaç kullanımı, 1. Baskı [Rational Use of Medicine]. T.C. Sağlık Bakanlığı Sağlık Araştırmaları Genel Müdürlüğü Yayını, Ankara. 2013, pp 8-141.

4. 4.Holloway K, van Dijk L. The World Medicines Situation 2011-Rational use of medicines. World Health Organization (WHO), Geneva. WHO/EMP/MIE 2011; 2.2.

5. 5.Akıcı A. Akılcı ilaç kullanımının genel ilkeleri ve Türkiye'deki güncel durum. Turkiye Klinikleri J Pharmacol-Special Topics 2015; 3: 1-10.

6. Akici A, Kalaca S, Goren MZ, Akkan AG, Karaalp A, Demir D, Ugurlu U, Oktay S. Comparison of rational pharmacotherapy decision-making competence of general practitioners with intern doctors. Eur J Clin Pharmacol 2004; 60:75-82
7. Basaran NF, Akici A. Aspects of physicians' attitudes towards the rational use of drugs at a training and research hospital: A survey study. Eur J Clin Pharmacol 2013; 69: 1581-7.

8. Hossaini-zadeh M. Current concepts of prophylactic antibiotics for dental patients. Dent Clin North Am 2016; 60:473-82.

9. Glenny AM, Oliver R, Roberts GJ, Hooper L, Worthington HV. Antibiotics for the prophylaxis of bacterial endocarditis in dentistry. Cochrane Database Syst Rev 2013; CD003813.

10. Laskarides C. Update on analgesic medication for adult and pediatric dental patients. Dent Clin North Am 2016;60:34766.

11. De Vries TP, Henning RH, Horgerzeil HV, Fresle HV. Guide to Good Prescribing: A Practical Manual. World Health Organization, Geneva 1994;14-18.

12. Akici A, Kalaca S, Ugurlu MU, Karaalp A, Cali S, Oktay S. Impact of a short postgraduate course in rational pharmacotherapy for general practitioners. Br J Clin Pharmacol 2004; 57:310-21.

13. Jain S, Upadhyaya P, Goyal J, Kumar A, Jain P, Seth V, Moghe VV. A systematic review of prescription pattern monitoring studies and their effectiveness in promoting rational use of medicines. Perspect Clin Res 2015; 6: 86-90. 
14. Akıcı A, Gelal A, Erenmemişoğlu A, Melli M, Babaoğlu M, Oktay Ş. Akılcı ilaç kullanımı eğitimi uygulama sürecinde Türkiye'deki tıp fakültelerinde farmakoloji anabilim dallarının durumunun incelenmesi. Tip Eğitimi Dünyası 2011;10: 11-20.

15. Akici A, Gören MZ, Aypak C, Terzioğlu B, Oktay S. Prescription audit adjunct to rational pharmacotherapy education improves prescribing skills of medical students. Eur J Clin Pharmacol 2005;61:643-50.

16. Ross S1, Loke YK. Do educational interventions improve prescribing by medical students and junior doctors? A systematic review. Br J Clin Pharmacol 2009; 67: 662-70.

17. Akıcı A, Dülger GA, Toklu HZ, Uysal MK. the role of the doctor and pharmacist in improving patient compliance in the process of rational drug use. Türkiye Aile Hekimliği Derg 2011;14: 139-45.

18. Toklu HZ. Rational use of medicine in pharmacy practice. Turkiye Klin J Pharmacol-Special Top 2015;3:74-83.

19. Karki AJ, Holyfield G, Thomas D. Dental prescribing in Wales and associated public health issues. Br Dent J 2010;210: 21.

20. Cope A, Chestnutt I. Inappropriate prescribing of antibiotics in primary dental care: Reasons and resolutions. Prim Dent J 2014;3:33-7.

21. Poveda Roda R, Bagan JV, Sanchis Bielsa JM, Carbonell Pastor E. Antibiotic use in dental practice. A review. Med Oral Patol Oral Cir Bucal 2007;12:186-92.

22. Combating antibiotic resistance. J Am Dent Assoc 2004;135:484-7.

23. Aldous JA, Engar RC. Analgesic prescribing patterns in a group of dentists. Gen Dent 2000;48:586-90.

24. Tanwir F, Marrone G, Tariq A, Lundborg CS. Diagnosis and prescribing pattern of antibiotics and painkillers among dentists. Oral Health Prev Dent 2015;13:75-83.

25. Jayadev M, Karunakar P, Vishwanath B, Chinmayi SS, Siddhartha P, Chaitanya B. Knowledge and pattern of antibiotic and non narcotic analgesic prescription for pulpal and periapical pathologies- A survey among dentists. J Clin Diagn Res 2014;8:10-4.

26. Kaptan RF, Haznedaroglu F, Basturk FB, Kayahan MB. Treatment approaches and antibiotic use for emergency dental treatment in Turkey. Ther Clin Risk Manag 2013;9:443-9.

27. Araghi S, Sharifi R, Ahmadi G, Esfehani M, Rezaei F. The study of prescribing errors among general dentists. Glob J Health Sci 2016;8:32-43.

28. Oberoi SS, Dhingra C, Sharma G, Sardana D. Antibiotics in dental practice: How justified are we. Int Dent J 2015;65:4-10.

29. Yılmaz M, Kırbıyıkoğlu Fİ, Ariç Z, Kurşun B. Bir diş hekimliği fakültesi hastanesi'ne başvuran bireylerin akılcı ilaç kullanımlarının belirlenmesi. ERÜ Sağlık Bilimleri Fakültesi Derg 2014; 2: 39-47.

30. Koyuncuoğlu C, Kırmızı Nİ, Ceyhan İ, Akıcı A. diş hekimliği kliniklerine başvuru öncesinde hastaların ilaç kullanımı ile ilgili tutumlarının araştırılması. Marmara Pharm J 2017 21: (Baskıda).

31. Aksoy M, Alkan A, İsli F. Sağlık Bakanlığı'nın Akılcı İlaç Kullanımını Yaygınlaştırma Faaliyetleri. Turkiye Klinikleri J Pharmacol Special Topics 2015;3: 19-25.
32. Aydın M, Koyuncuoğlu CZ, Kılboz MM, Akıcı A. Diș hekimliğinde akılcı antibiyotik kullanımı. Turkiye Klinikleri J Pharmacol 2017; 23: 33-47.

33. Hogerzeil HV, Barnes KI, Henning RH, Kocabasoglu YE, Möller H, Smith AJ, Summers RS, de Vries TPGM. Teacher's Guide to Good Prescribing. World Health Organization, Geneva, 2001.

34. Akici A, Oktay Ş. Rational pharmacotherapy and pharmacovigilance. Curr Drug Safety 2007;2:65-9.

35. Kayaalp O. Türkiye İlaçla Tedavi Kılavuzu 2011-2012 Formüleri (TİK-6) [Turkey National Medicine Formulary 2011-2012]. Pelikan Yayıncılık, Ankara. 2011, pp 30-35: 350411.

36. Akıcı A, Gelal A. Birincibasamakta nonsteroid antienflamatuar ilaçların akılcı kullanımı. Türkiye Klinikleri, Aile Hekimliği Dergisi Birinci Basamakta Ağrıya Yaklaşım Özel Sayısı 2011; 2:61-70.

37. Inotai $\mathrm{A}$, Hankó $\mathrm{B}$, Mészáros $\mathrm{A}$. Trends in the nonsteroidal anti-inflammatory drug market in six CentralEastern European countries based on retail information. Pharmacoepidemiol Drug Saf 2010;19:183-90.

38. Fosbøl EL, Gislason GH, Jacobsen S, Abildstrom SZ, Hansen ML, Schramm TK, et al. The pattern of use of non-steroidal anti-inflammatory drugs (NSAIDs) from 1997 to 2005: A nationwide study on 4.6 million people. Pharmacoepidemiol Drug Saf 2008;17:822-33.

39. Kovac SH, Houston TK, Weinberger M. Inappropriate nonsteroidal anti-ınflammatory drug use: prevalence and predictors. J Patient Saf 2010;6:86-90.

40. Sostres C, Gargallo CJ, Arrovo MT, Lanas A. Adverse effects of non-steroidal anti-inflammatory drugs (NSAIDs, aspirin and coxibs) on upper gastrointestinal tract. Best Pract Res Clin Gastroenterol 2010;24:121-32.

41. 41.Smith HS, Lesar TS. Analgesic prescribing errors and associated medication characteristics. J Pain 2011;12:29-40.

42. 42.Brunton LL, Parker KL. Section IV: Autocoids: Drug Therapy of Inflammation, Chapter 26: Analgesic-Antipyretic and Antiinflammatory Agents; Pharmacotherapy of Gout. In: Goodman \& Gilman's Pharmacology, 11th ed. Eds: Brunton LL, Parker KL. McGrawHill Companies. United States. 2006; pp 430.

43. 43.Cunha-Cruz J, Milgrom P, Shirtcliff RM, Huebner CE, Ludwig S, Allen G, Scott J. "Everybody brush!": protocol for a parallel-group randomized controlled trial of a familyfocused primary prevention program with distribution of oral hygiene products and education to increase frequency of toothbrushing. JMIR Res Protoc 2015;4: 58.

44. Yaacob M, Worthington HV, Deacon SA, Deery C, Walmsley $\mathrm{AD}$, Robinson PG, Glenny AM. Powered versus manual toothbrushing for oral health. Cochrane Database Syst Rev 2014; 2281.

45. Sambunjak D, Nickerson JW, Poklepovic T, Johnson TM, Imai P, Tugwell P,

46. Worthington HV. Flossing for the management of periodontal diseases and dental caries in adults. Cochrane Database Syst Rev 2011; 8829.

47. Akıcı A, Kalaça S. Topluma Yönelik Akılcı İlaç Kullanımı. 1. Baskı. Editör: Akıcı A. T.C. Sosyal Güvenlik Kurumu 
Başkanlığı, Ankara. 2013.

48. Akici A, Kalaca S, Ugurlu MU, Toklu HZ, Iskender E, Oktay S. Patient knowledge about drugs prescribed at primary healthcare facilities. Pharmacoepidemiol Drug Saf 2004;13:871-6.

49. Basaran NF, Akici A. Patients' experience and perspectives on the rational use of drugs in Turkey: a survey study. Patient Prefer Adherence 2012;6:719-24.
50. Arslan LS, Semin S. Attitudes and practices of primary healthcare center patients about drug use in Turkey. Patient Educ Couns 2006;62:250-9.

51. Akici A, Mollahaliloglu S, Ozgulcu S, Donertas B, Alkan A. Assessment of health care service in terms of rational use of medicines delivered to patients in primary health care centres and public hospitals. Turkish Family Physician 2015;6:1-10. 